\title{
Extra! Extra! O caso do Metrorec revela como é operada a manipulação ideológica do discurso da QVT
}

\author{
Débora Coutinho Paschoal Dourado*
}

Cristina Amélia Carvalho*

Resumo

O objetivo deste artigo é revelar os interesses organizacionais subjacentes à lógica organizacional da qualidade de vida no trabalho (QVT). Para tanto, aplica a técnica de análise crítica do discurso (ACD) ao programa de QVT do Metrovec, empresa responsável pelo metrố no estado de Pernambuco. Categorias discursivas servem de base para operacionalizar tal análise, possibilitando identificar como o discurso da QVT emprega recursos retóricos ideologicamente operados. A técnica possibilita desvendar como esse discurso oculta de maneira eficaz a dominação presente na relação empresal trabalhador. Permite também compreender de que maneira tal discurso visa conseguir desse trabalhador participação e comprometimento com a solução dos problemas em seu desempenho causados pelos efeitor negativos do trabalho na empresa.

Palarras-chave: qualidade de vida no trabalho, lógica organizacional; análise crítica do discurso.

\begin{abstract}
This paper aims at discussing the organizational interest when supporting the stated logics of Quality of Life at Work (QLW). This study applies the discourse critical analysis method in Metrorec's QLW program. Metrorec is a metro company based in PernambucoBrazil. Discursive categories allowed reaching the rhetorical arguments used by $Q \angle W$ ideology, which in its speech effectively makes the existing domination in employeescompany relation fade away. The domination discourse of QLW looks at participation and commitment of the employee while covering up the negative effects of work over its performance.
\end{abstract}

Key words: quality of working life; organizational logic; discourse critical analysis.

\footnotetext{
* Doutoranda do PROPAD/UFPE - Pesquisadora do Observatório da Realidade Organizacional, Professora do Departamento de Ciências Administrativas da UFPE - Av. dos Economistas, s/n - $1^{\circ}$ andar- Sala D37 - Cidade Universitária - Recife/PE - 50670-901 -ddourado@hotlink.com.br

** Doutora em administração pela Universidad de Córdoba, Espanha - Coordenadora do Observatório da Realidade Organizacional e Professora do Programa de Pós-graduação em Administração da UFPE - Av. dos Economistas, s/n - $1^{\circ}$ andar- Sala D37 - Cidade Universitária - Recife/PE - 50670-901 E-mail: cris_carvalho@uol.com.br
} 


\section{O discurso e a análise crítica do discurso}

O reconhecimento do papel intencional do discurso no comportamento dos indivíduos nas organizações é a base deste artigo. Arendt (2003) explica que

nenhuma outra atividade humana precisa tanto do discurso quanto a ação. Na ação e no discurso os homens mostram o que são e revelam ativamente suas identidades pessoais e singulares, e assim, apresentam-se ao mundo humano. (Ibid., p.192).

Portanto, é através do discurso que os homens se revelam. Assim, é preciso esclarecer que o discurso é considerado uma forma de "prática social e não uma atividade puramente individual ou reflexa de variáveis situacionais”, haja vista que se reconhece nas práticas administrativas, o que Arendt denomina de ação.

Essa perspectiva fundamenta a teoria social do discurso, composta por um modelo de três dimensões: a prática social, a prática discursiva e o texto que tem como propósito a organização da análise (FAIRCLOUGH, 2001, p.90).

Figura 1

Concepção tridimensional do discurso

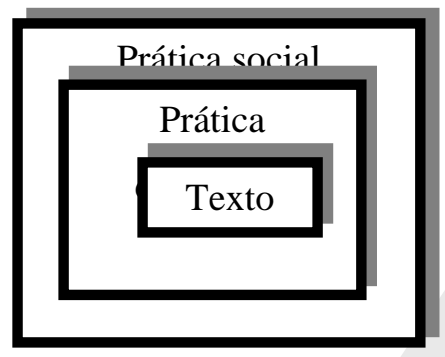

Fonte: Fairclough (2001).

De acordo com esse modelo, o texto vem imerso e a serviço das práticas discursivas que, por sua vez, são manipuladas estrategicamente para a configuração de determinadas práticas sociais que buscam a conservação dos interesses que representam.

Embora se reconheça o poder explicativo do modelo tridimensional de Fairclough (2001), o enquadre proposto por Chouriaraki e Fairclough (1999) - tabela 1 - pareceu ampliar o caráter emancipatório da teoria. Ele não apenas possibilita análises mais abrangentes, mas estimula, mais do que o modelo tridimensional, o interesse pela análise de práticas problemáticas decorrentes de relações de exploração e, também, ajuda a apreender melhor a articulação entre o discurso e outros elementos sociais na formação de práticas sociais (RESENDE; RAMALHO, 2006).

Na medida em que parte da interpretação social dos sentidos, ou seja, da investigação sobre o uso da linguagem na construção destes, a análise crítica do discurso busca compreender o texto em seu contexto social e na historicidade de suas proposições. O principal interesse dessa vertente analítica são as relações de produção do sentido do discurso, cujo mecanismo principal é o desprendimento do texto em si, deslocando a análise para a busca das regras de coerência que estruturam o universo dos discursos dentro da organização investigada (GODOI, 2005).

Misoczky (2005) adverte que é notadamente no momento atual de desenvolvimento do capitalismo, cujas esferas de atuação têm sido expandidas, que a utilização da linguagem e de seus artefatos tem sido mais relevante, visando desvendar essas ferramentas no âmbito das organizações e de suas práticas gerenciais. 
Assim, o discurso gerencial contemporâneo vem sendo representado por meio de vários recursos, entre os quais se identifica a QVT.

Diante desses argumentos, para fins de análise do discurso da QVT como recurso estratégico da moderna gestão de pessoas nas organizações, adotou-se o seguinte esquema, que norteou a análise, partindo de sua desconstrução como prática social, associada a uma conjuntura específica e a outras práticas relevantes, tal como mostra a tabela 1 . 


\section{Tabela 1}

\section{O enquadre para ADC de Chouriaraki e Fairclough}

\begin{tabular}{l|l|l}
\hline 1. Um problema & \multicolumn{2}{|l}{} \\
\hline \multirow{4}{*}{$\begin{array}{l}\text { 2. Obstáculos a } \\
\text { serem superados }\end{array}$} & $\begin{array}{l}\text { (b) Análise da prática em } \\
\text { particular }\end{array}$ & \begin{tabular}{l} 
(i) Práticas relevantes \\
\cline { 2 - 2 }
\end{tabular} \\
\cline { 2 - 2 } & $\begin{array}{l}\text { (ii) Relações do discurso com outros momentos da } \\
\text { prática }\end{array}$ \\
\hline 3. Função do problema na prática & (i) Análise estrutural \\
\cline { 2 - 2 } & (ii) Análise interacional \\
\hline 4. Possíveis maneiras de superar obstáculos \\
\hline 5. Reflexão sobre a análise \\
\hline
\end{tabular}

Fonte: Chouriaraki e Fairclough (1999, p.60)

De acordo com esse esquema, é possível observar que, em geral, o discurso é concebido para fins específicos: resolver um problema determinado ou desenvolver uma atividade necessária no âmbito das organizações.

Para auxiliar no julgamento do problema, Widdicombe (1993, p.254) sugere que se considerem as maneiras como as coisas são ditas como potenciais soluções de problemas. O trabalho do analista torna-se, portanto, o de identificar cada problema e como o que é dito constitui uma solução, conferindo dessa forma a consistência e a validade necessárias a um trabalho dessa natureza.

O uso da linguagem como prática social é um modo de ação historicamente situado, que além de ser construído socialmente também é constitutivo de identidades sociais, de relações sociais e de sistemas de conhecimento e crença. Resende e Ramalho (2006) esclarecem

nisso reside a dialética entre discurso e sociedade: o discurso é moldado pela estrutura social, mas é também constitutivo da estrutura social. Não há, portanto, uma relação externa entre linguagem e sociedade, mas uma relação interna e dialética. (Ibid., p.27)

Para tanto, é feita uma análise da conjuntura, ou seja, de acontecimentos históricos e estruturais relacionados ao problema, o que possibilita compreender as causas ou motivações do uso daquele tipo de discurso. Esse exame, incorporado à análise da prática em particular adotada e do discurso, propriamente, delineia as estratégias discursivas utilizadas para superarem as resistências à solução daquele problema sobre o qual o discurso se propõe a agir.

É a análise crítica sobre a função do problema e das possíveis maneiras que podem ser adotadas para superar o obstáculo que revela a arquitetura do discurso e de todas as suas ferramentas textuais ideológicas.

Olivo e Misoczky (2003) explicam que é preciso compreender os jogos de linguagem e as estratégias discursivas realizadas pelos atores que disputam o campo. Nesse sentido, as práticas discursivas se valem de estratégias lingüísticas como ferramentas discursivas, presentes de várias maneiras, cuja classificação subsidia o entendimento sobre os reais interesses discursivos. A classificação das estratégias discursivas realizada por esses autores, adaptada de Fairclough (2000; 2001) são apresentadas na tabela 2. 
Tabela 2

Práticas discursivas orientadoras da análise de discurso

\begin{tabular}{ll}
\hline Antítese & Estabelece contrastes que são opostos, mas não divergentes. \\
\hline Colocação & $\begin{array}{l}\text { São coocorrências entre palavras em um texto. Identificadas pela freqüência com que } \\
\text { um adjetivo é utilizado para modificar um substantivo. }\end{array}$ \\
\hline Equivalência & São estabelecidas utilizando-se listas ou substituições, como se fossem sinônimos. \\
\hline Metáfora & A metáfora tem a função de criar uma analogia entre um conceito e outro. \\
\hline Modalidade & $\begin{array}{l}\text { Especifica o nível de comprometimento. Tem a ver com pretensão de verdade e/ou } \\
\text { com obrigação (não pode existir qualquer outra alternativa). }\end{array}$ \\
\hline Tom/Modos & $\begin{array}{l}\text { Declarativo, imperativo e interrogativo. Preferências sistemáticas podem ser } \\
\text { sociológica ou ideologicamente significantes. }\end{array}$ \\
\hline Nominalização & $\begin{array}{l}\text { Representa um processo com um nome, um substantivo, tornando esse processo } \\
\text { genérico e vago. A responsabilização pode ser obscurecida com a nominalização. }\end{array}$ \\
\hline Excesso de Palavras & Proliferação de diferentes palavras na mesma área de significado. \\
\hline Transitividade & $\begin{array}{l}\text { O maior interesse está em perceber que os atores são omitidos, podendo fazê-lo } \\
\text { porque são óbvios ou porque há intenção dos agentes e responsabilidades. }\end{array}$ \\
\hline Pressuposição & $\begin{array}{l}\text { Textos são sempre uma mistura de significados implícitos e explícitos. Às vezes, o } \\
\text { que é pressuposto (tido como dado) não está em debate (é mero senso comum). } \\
\text { Outras são contenciosas. Elas pressupõem (assumem) determinadas coisas que são } \\
\text { questionáveis }\end{array}$ \\
\hline Pronomes & $\begin{array}{l}\text { A questão é saber quem exatamente é incluído? Quem são esses atores sociais que se } \\
\text { encarregam do problema? Quais as propriedades sociais desses atores? }\end{array}$ \\
\hline Ethos/Estilo & $\begin{array}{l}\text { Formas sutis de argumentação persuasivas que jogam com relações de poder (apelam } \\
\text { à emoção). Estilos têm a ver com o desempenho geral: com entidades políticas e } \\
\text { valores; com o modo como atinge consenso; como ele representa o mundo social, o } \\
\text { processo governamental e político; e também como projeta a identidade particular a } \\
\text { valores específicos. }\end{array}$ \\
\hline
\end{tabular}

Fonte: adaptado de Misoczky (2002), a partir de Fairclough (2000, 2001).

Essas categorias serviram de base para a operacionalização da análise crítica do discurso da QVT, e constam do programa de Qualidade de Vida no Trabalho do Metrorec, apresentado a seguir. Essas categorias serviram de base para a operacionalização da análise crítica do discurso verificado no programa de qualidade de vida no trabalho do Metrorec, apresentado a seguir.

\section{O discurso de um programa de qualidade de vida no trabalho}

O programa de qualidade de vida no trabalho, com todo seu histórico, justificativa, contexto e detalhamento, consta de um documento institucional denominado Programa de Qualidade de Vida do Metrorec, publicado em 2005. Em sua apresentação, o documento discorre sobre o que motivou o programa e seus principais dados históricos. Em seguida, descreve suas principais ações e dimensões, seu marco de referência e o cronograma físico financeiro. Com base nesse documento, é possível uma análise critica do discurso organizacional sobre QVT.

"Motivada pela crença de que a realidade que molda o comportamento do homem também pode ser modificada a partir do comportamento daqueles que assumem o papel de escrever uma história diferente, mesmo quando todo um contexto faz crer que a correnteza é que leva a canoa, a equipe do Departamento de Recursos Humanos do METROREC resolveu reunir esforços e construir uma política permanente voltada para o bem-estar funcional dos colaboradores do Recife.” (METROREC, 2005, p.1) 
Quando confrontamos o referido documento com o esquema proposto por Chouliaraki e Fairclough (1999, p.60), já mostrado na tabela 1, percebemos a lógica e os interesses organizacionais do programa, operacionalizados pelo uso de ferramentas textuais específicas. Tais ferramentas são analisadas a partir da classificação das práticas discursivas apresentadas na tabela 2.

Os recursos textuais empregados revelam uma tentativa de dissuasão dos trabalhadores. Nos trechos iniciais do documento, constata-se a adoção de um ethos persuasivo que recorre a expressões apelativas, é imbuído de juízo de valor e induz o indivíduo ao assentimento, caso queira, de fato, fazer parte de uma equipe que pretende escrever uma história diferente. Quem propõe o programa é o órgão de recursos humanos. Ademais, o documento parte da pressuposição de que a realidade pode ser modificada por quem assume a responsabilidade de escrever uma história diferente, o que é feito suprimindo-se o debate e de forma contenciosa, pois assume como verdade o que é questionável para alguns.

O esquema aponta para o fato de que comumente um discurso existe visando à solução de um problema ou de uma atividade específica. Dessa forma, é bastante relevante descobrir o problema que o discurso organizacional - da QVT no Metrorec - visa solucionar.

De acordo com o documento, a motivação para instaurar o programa foi a crença na importância "do bem-estar funcional dos colaboradores" (METROREC, 2005, p.1). Contudo, as entrevistas realizadas revelaram que a principal causa do surgimento do programa foram os altos índices de insatisfação no trabalho, gerada por anos de estagnação funcional (definidos por um plano de cargos e salários obsoleto), por uma defasagem salarial crônica e por elevados indicadores de doenças ocupacionais, tais como stress, depressão e alcoolismo, além de outras enfermidades, que por seu turno, estavam causando graves problemas de produtividade à organização.

Portanto, essa análise preliminar sobre as inconsistências entre os discursos denuncia que o programa de QVT do Metrorec surgiu de uma tentativa de solucionar esses problemas organizacionais. Contudo, este trecho faz uso de ferramentas lingüísticas que tentam confundir o trabalhador e sua comunidade, convencendo-os de que o objetivo gerencial funda-se na preocupação com o seu bem-estar.

“Assim, paulatinamente, o Comitê Executivo foi estruturando uma linha de pensamento capaz de configurar o desejo coletivo daqueles que se fizeram representar..." (METROREC, 2005, p.1)

No trecho que discorre sobre o processo evolutivo do programa, o documento faz alusão à formação do comitê executivo, grupo responsabilizado pelo planejamento e pela proposição de ações de QVT. Na sua redação, faz uso de uma formação textual que confere ao comitê legitimidade de representação do desejo da coletividade. Ao fazer isso, usa uma modalidade textual que não permite outra possibilidade senão a de que o comitê executivo representa o desejo de todos os trabalhadores representados por esse grupo. Também no que tange à representatividade do comitê, o documento faz uso do excesso de palavras, ou seja, da proliferação de diferentes termos com o mesmo significado, opção textual indicativa de uma preocupação ideológica intensiva de demonstrar a legitimidade do grupo. Todavia, alguns questionamentos colocam em cheque essa "verdade" defendida pelo texto: quem elegeu os membros do comitê? Os trabalhadores foram consultados sobre sua composição?

Para explicar os interesses organizacionais ao propor ações de QVT para os indivíduos que nela trabalham, o texto apresenta utensílios ainda mais contundentes.

"Qualidade de vida não é algo que está apenas no plano individual, ela é mais que isso. Perpassa na direção do Bem-Estar Coletivo. É algo Comunitário. Faz parte de uma cadeia entrelaçada da qual a organização faz parte. [...] Com toda certeza, as organizações jamais existiriam sem as pessoas que lhes dão vida, dinâmica, impulso, criatividade e racionalidade. Na verdade, cada uma das partes depende da outra. Uma relação de interdependência na qual há benefícios recíprocos. Hoje, o assunto Qualidade de Vida no Trabalho passou a ser pauta diária. Não há como dissociar o Trabalhador do Homem. O Homem passa a ser, cada vez mais, o principal ativo das organizações” (METROREC, 2005, p.2) 
O trecho explicita o tom/modo declarativo, com forte conteúdo ideológico. Na verdade, são orações usadas como recursos retóricos ajustados para convencer da "responsabilidade" da empresa pelos seus trabalhadores, justificando o porquê dessa invasão da organização a dimensões da vida humana. Confunde os seus trabalhadores quando afirma com esse tom que o interesse da organização é o bem-estar coletivo.

Embora use desse tipo de abordagem, o jogo retórico mostra contradições internas na concepção sobre qualidade de vida, desnudando os seus verdadeiros interesses. Por um lado, manifesta seu fundamento no "bem-estar coletivo" e "no comunitário" e de outro, defende o papel instrumental das pessoas para a organização, transportando-se de uma esfera a outra da vida humana, como se ambas tivessem o mesmo caráter.

Justifica sua postura afirmando que "não há como dissociar o trabalhador do homem". Todavia, à medida que fala sobre a utilidade das pessoas para os fins organizacionais, revela o que pretende sobre os homens no âmbito organizacional: afirma que as pessoas dão-lhes [às empresas] "vida, dinâmica, impulso, criatividade e racionalidade", mas na realidade, quer tirar proveito dessas contribuições e imprimir o comportamento esperado nos trabalhadores.

Assim, também assume conteúdo de pressuposição na medida em que conclui, estrategicamente, por uma pretensão de verdade ao conferir ao trabalhador a condição de "principal ativo" das organizações, tal como suas máquinas, sua matéria-prima e seu capital. Dessa maneira, refere-se ao homem como cerne das organizações e de sua existência, confundindo-o com seus recursos instrumentais necessários, mas cuja relevância é, na verdade, sua utilidade para incrementar os índices de lucratividade.

Ao apresentar a origem do programa e de uma política permanente de QVT, o documento menciona os desafios enfrentados e os esforços empreendidos.

"A discussão sobre a criação de uma política permanente sobre Qualidade de Vida no Trabalho veio sendo desdobrada ao longo de 01 (um) ano, quando em outubro de 2004 foi dado início a um plano de criação dessa política. Naquele momento, tinha-se conhecimento de que tal façanha não se desenhava da noite para o dia. Havia necessidade de se extrair do campo do sonho algo que pudesse ser aplicado na prática cotidiana do Departamento de Recursos Humanos, mas que tivesse uma conotação ampla e expressasse o desejo de uma coletividade e não apenas de um departamento.” (METROREC, 2005, p. 3)

Logo de início, o texto revela que se tratou de interesse do órgão de recursos humanos a criação de uma política permanente, cujo uso da ferramenta discursiva de nominalização, atribui responsabilidade e autoria a uma "política permanente de qualidade de vida no trabalho" às ações empreendidas nesse campo, desvinculando-as do departamento. Assim, doravante esse substantivo torna o processo genérico e vago, obscurecendo a responsabilização pelas iniciativas de QVT. Nesse ponto, também faz uso da transitividade, ofuscando os atores envolvidos no desenvolvimento dessas práticas.

Que interesse se oculta por trás de uma responsabilidade evasiva e genérica? Se evidencia, assim, o propósito de naturalizar as práticas de QVT entre os trabalhadores, deixando que façam parte do comportamento esperado desses indivíduos. Nesse momento, é exercida a ideologia e sua função reprodutora. Essa abordagem gera uma uniformidade de respostas dos trabalhadores, que são, precisamente, os objetivos das teorias gerencialistas do comportamento organizacional.

Nesse sentido, desvela-se o principal interesse dos programas de QVT como prática do comportamento organizacional: a geração e manutenção da conduta uniforme nos trabalhadores. Evidentemente, essa uniformidade não pode ser explicada pela harmonia de interesses preconizada pela economia clássica. Pode ser entendida, isto sim, através da realidade do conflito, tão perseguido pelas sucessivas tentativas de "socialização do homem", exercidas através do discurso do agente dominador, a organização, sobre os sujeitos, os trabalhadores (ARENDT, 2004, p.54).

Também a descrição da origem do programa de QVT na organização aponta para o uso dos mecanismos retóricos. 
"Usando a racionalidade necessária sem impossibilitar a fluidez da emoção que dava vazão ao sonho de construir um espaço saudável, a equipe de Coordenação do Programa criou o Comitê Executivo para dar forma àquele plano de ação, e juntos elencaram quatro pilares como primordiais: Físico - Mental - Social Espiritual. Cada um desses pilares suscitou discussões e findaram em proposições objetivas de como fomentar sua aplicabilidade. Assim, os programas sugeridos a seguir são frutos desse Comitê, e que vem atender aos anseios dos colaborares do METROREC, detectados pela atuação da equipe do Departamento de Recursos Humanos e pelo resultado da pesquisa realizada." (METROREC, 2005, p.3)

Nesse trecho, a força simbólica dos termos - "usando a racionalidade necessária sem impossibilitar a fluidez da emoção que dava vazão ao sonho de construir um espaço saudável” - é utilizada para enaltecer a preocupação e o empenho da equipe de recursos humanos no empreendimento do programa de QVT, cujo uso revela o ethos como uma prática discursiva que confere poder apelativo através do emocional. O uso desse tipo de abordagem visava fomentar que as intenções sobre o programa provém dos sentimentos e das emoções e não dos interesses econômicos. Nesse momento, ainda apela para a justificativa, sob a forma de pressuposição, de que valer-se da racionalidade é condição necessária à consecução do plano, argumentando que isso se justifica pelo valor do objetivo final, que é construir um “espaço saudável” de trabalho.

São muito freqüentes, ao longo do documento, trechos que fazem referência à composição do comitê de QVT, à forma como foi constituído e ao levantamento sobre as principais necessidades encontradas no corpo funcional da organização. Também este fragmento intenta reforçar o caráter participativo na formação do programa, atribuindo verdade a uma modalidade assumida como democrática. Ao afirmar que "a equipe de coordenação do programa criou o comitê executivo para dar forma àquele plano de ação, e juntos elencaram quatro pilares", menciona que os pilares foram definidos tanto pela coordenação do programa quanto pelo comitê executivo, dando a impressão de que se tratava de uma relação de igualdade de poder e comunhão de interesses.

Adiante, quando o documento afirma que as ações apresentadas no programa representam as indicações feitas pelo próprio comitê em resposta às necessidades dos seus trabalhadores ("os programas sugeridos a seguir são frutos desse Comitê, e [...] vêm atender aos anseios dos colaborares do Metrorec"), recorre ao excesso de palavras, outro recurso retórico, que indica a preocupação ideológica de convencer que a formação do grupo e a concepção do programa foram feitas de maneira democrática e representativa.

Quanto à definição dos pilares que deram origem às dimensões propostas por ele, é preciso questionar sua propriedade. O texto inclui elementos de esferas da vida humana mais particulares e inalienáveis. Afinal, porque aborda temas como a socialização, o equilíbrio mental e, principalmente, a espiritualidade? O que resta, então, ao indivíduo?

O documento também apresenta as principais ações a serem desenvolvidas pelo programa, assim como faz uma ressalva à possibilidade de ajustes em decorrência de novas demandas que possam surgir por parte dos trabalhadores.

"Apresentamos os programas que foram detectados como prementes pelo Comitê Executivo. São 05 (cinco) Projetos que compõem a atual formatação desta Política de Recursos Humanos. Porém, outros programas poderão vir a compor uma nova estrutura ideológica para ser aplicado posteriormente, uma vez que esta Política deverá estar em consonância com novas demandas, sendo sempre necessária a sua reavaliação para manter sua contemporaneidade. Os projetos elencados como primordiais são: Planejamento Financeiro e Orçamento Doméstico, Saúde e Vida, Prevenção e Tratamento do Alcoolismo, Atividades Físicas, Alimentação Saudável." (METROREC, 2005, p.4)

Novamente, justifica a escolha das ações a serem desenvolvidas classificando-as como mais "prementes", através do excesso de palavras e de repetições de termos entre as partes do texto.

O uso de expressões retóricas como "outros programas poderão vir a compor", "ser aplicado posteriormente", "esta política deve estar em consonância com novas demandas", "necessária sua reavaliação" e "manter sua contemporaneidade" enfatiza o caráter provisório da proposta e é um meio de garantir a aprovação daqueles 
que não se sentirem considerados por aquelas ações. Portanto, o intento subjacente a essas justificativas indica uma relativa falta de legitimidade das iniciativas de QVT do programa, que recorre aos argumentos de transitividade dessas propostas para acenar com chances de contemplação dos reais interesses dos trabalhadores em versões posteriores. Assim, é possível inferir que o interesse dito premente é o organizacional. não o coletivo (dos trabalhadores).

Por trás de cada uma das ações propostas está o intento de tratar dos problemas ocupacionais que vêm atravancando a produtividade e o desempenho na organização

As ações de planejamento financeiro e orçamento doméstico foram adotadas para remediar o alto nível de endividamento dos trabalhadores, o qual tem gerado problemas ocupacionais sérios como alcoolismo, estresse e hipertensão, entre outros. Agregadas a essas ações, foram desenvolvidas seções voltadas para o orçamento doméstico dos funcionários, atingindo, portanto, a própria vida familiar do trabalhador.

As ações de saúde e vida voltaram-se para o tratamento dos efeitos mais evidentes do trabalho sobre o indivíduo. Por funcionar em turnos consecutivos e contar com um significativo número de trabalhadores em atividades operacionais (operação e manutenção de máquinas e equipamentos), o Metrorec precisava que seus trabalhadores recuperassem um nível de saúde que lhes possibilitasse manter índices médios de desempenho, daí a proposição dessa dimensão na política institucional de QVT.

Entre as doenças ocupacionais, o alcoolismo foi reconhecido como o mais grave obstáculo ao desempenho no trabalho, tanto pela pesquisa encomendada e realizada por uma consultoria quanto pelos relatórios da gerência de assistência social da empresa (ENTREVISTADO B). Assim, embora tivesse sido definida uma dimensão voltada para saúde e vida, foi necessário propor no programa uma ação que envidasse esforços exclusivos para o tratamento dessa moléstia.

As atividades físicas e a alimentação saudável visavam tratar o alto grau de sedentarismo evidenciado pelos diagnósticos e pelos relatos à gerência de assistência social, minimizando os efeitos negativos na produtividade. Especificamente, o programa de alimentação saudável - através de cursos sobre reaproveitamento de alimentos -, ao corrigir a deficiência nutricional do trabalhador, dentro e fora do trabalho, muitas vezes ocasionada pelos baixos salários e pelo alto nível de endividamento destes, tenta resolver as decorrências da má alimentação no seu desempenho.

É preciso compreender a forma como opera a lógica da QVT. As ações organizacionais são concebidas com fins econômicos, levando em conta os interesses do homem apenas quando isso coincide com a busca por resultados organizacionais. Tais ações são concebidas, fundamentalmente, para tratar do que representa um obstáculo ao desempenho no trabalho. Fica evidente, portanto, que a lógica administrativa da QVT é instrumental, uma vez que objetiva sobrepujar as constantes dificuldades geradas pelo conflito homem/empresa.

Quando define o marco de referência do programa de QVT da organização, o documento assume os pressupostos do programa como esquemas norteadores das decisões de curto, médio e longo prazos. Dessa maneira, não se abre à discussão e cria consenso em torno desses princípios. Na realidade, manipula um conjunto de determinações, para justificar a implantação do programa e ao mesmo tempo convencer gestores, os que atuam no órgão de RH e, claro, os trabalhadores. 
"A Política de Qualidade de Vida no Trabalho CBTU/METROREC estabelece como objetivo estratégico o reconhecimento de que o FATOR HUMANO É PEÇA FUNDAMENTAL [maiúsculas do original] para obtenção de qualidade na prestação dos serviços oferecidos pela Empresa a seus usuários diretos e indiretos, conforme preceituado em sua MISSÃO, dando-lhe todo apoio necessário para o perfeito entendimento deste compromisso.

A Política de Qualidade de Vida no Trabalho CBTU/METROREC é uma CONVENÇÃO PERMANENTE [maiúsculas do original], focada na prevenção, promoção e assistência ao bem-estar funcional, buscando minimizar o grau de sofrimento físico, social e lou mental de seus colaboradores, que decorram da relação com o trabalho.

A Política de Qualidade de Vida no Trabalho CBTU/METROREC visa contribuir para a construção de uma comunidade capaz de reconhecer a VALORIZAÇÃO DAS RELAÇÕES HUMANAS [maiúsculas do original], respeitando a integridade física, social e mental de seus colaboradores, a partir de trabalhos de promoção de bem-estar" (METROREC, 2005, p.5)

A noção instrumental, atribuída de forma clara à participação dos indivíduos na organização e assumida no documento, evidencia o papel das pessoas na empresa, ao explicar a relação entre a qualidade na prestação dos serviços oferecidos e o apoio necessário dado pelo Metrorec. Assim, o programa se revela quanto à sua orientação e propósito.

As estratégias discursivas utilizadas - notadamente, na seção "Marco de referência" - permite identificar o uso dos termos para a criação de uma postura ideológica compulsória, voltada para a QVT, a partir de então. Faz uso, portanto, de uma modalidade discursiva impositiva, uma vez que especifica o nível de comprometimento necessário ao programa, estipulando, mesmo de forma sutil, a inexistência de outra possibilidade que não seja a de total adesão. O texto também recorre a termos como "convenção permanente" e "missão", adotando o excesso de palavras para fortalecer a posição ideológica de que a organização se compromete com a "prevenção, promoção e assistência ao bem-estar funcional”.

Esse estilo (ethos) discursivo assume o sofrimento no trabalho e os malefícios decorrentes, propondo-se a atacá-lo pela prática administrativa da QVT, um compromisso estratégico organizacional que tem a clara finalidade de reverter os resultados negativos que tal insatisfação no trabalho traz para a empresa. Nesse caso, o compromisso estratégico confere ao discurso um valor simbólico de sentido impositivo, necessário ao estabelecimento de uma política e práticas de recursos humanos até então preteridas, bem como à sua legitimação.

A operacionalização do programa também é descrita na seção "Marco de referência" e nela pode ser assinalado o uso das ferramentas discursivas. Para compreender os argumentos e abordagens da operacionalização, devese esmiuçar os elementos que a compõem. O texto menciona que a base das ações é a implantação de três programas: de prevenção, de promoção e de assistência. Ao assumir essa perspectiva ampla, visa contemplar as especificidades da condição social do trabalho dos vários indivíduos do corpo funcional. Uma vez que atinja a todos, a representação do individual passa a ser observada no discurso do organizacional.

"A Política de Qualidade de Vida no Trabalho CBTU/METROREC entende que os Projetos terão características diferentes e, portanto, durações variáveis em face da sua pertinência, e para isso serão levados em consideração os seguintes aspectos: Programas de Prevenção [negrito do original]: serão trabalhos pautados na particularidade de casos com foco individual e relevância coletiva, portanto serão de intervenção permanente. Programas de Promoção [negrito do original] - serão trabalhos pautados pela divulgação/propagação de conceitos, podendo estar atrelados a intervenções pontuais, mas concisos em sua temporalidade. Proqramas de Assistência [negrito do original] - serão trabalhos de amparo e reabilitação." (METROREC, 2005, p.5) 
Conceitualmente, a prevenção está atrelada ao impedimento da ocorrência do fato em si; portanto, aos efeitos do fato evitado. Assim, ao propor programas de prevenção, o discurso da QVT elimina a própria ocorrência de problemas ocupacionais que reduzem a produtividade e a qualidade dos serviços prestados. Portanto, trata-se de um mecanismo prescritivo que usa conteúdo ideológico para conduzir os comportamentos.

Os programas de promoção têm um cunho educativo, demonstrando serem um dos instrumentos mais evidentes de sua funcionalidade. A divulgação/propagação de conceitos imprime uma concepção de trabalho e desempenho ao quadro funcional da organização, fazendo uso de enunciados mobilizadores do senso comum, impregnados por modelos de conduta ordinários.

A análise dos programas de assistência permite assoalhar um dos fragmentos mais contundentes do discurso da QVT: o assistencialismo social inerente ao seu discurso. A que se propõe a empresa, ao amparar o trabalhador? Não seria dispô-lo em condições ideais de trabalho, colocá-lo apto ao desempenho de suas atribuições? Embora as práticas gerencialistas insistam no discurso do assistencialismo, articulado no discurso do papel social das empresas, observa-se o forte poder simbólico dessas expressões, imprimindo a naturalização de termos como “amparo e reabilitação" do trabalhador.

No tocante à implantação do programa e da política de QVT na organização, é possível observar a forte relação de poder implícita ao discurso, em relação a qual se identifica o uso de alguns mecanismos retóricos que tentam obscurecer essa relação.

"A Política de Qualidade de Vida no Trabalho da CBTU/METROREC visa assegurar que os projetos que integram o Programa Global de Qualidade de Vida do Metrorec sejam aplicados, cumprindo-se calendários estabelecidos para este fim, e para isso, irá prover os recursos necessários em sua dotação anual.

Para a concretização dessa Política, caberá a cada colaborador, independente do seu grau de conhecimento, esfera de poder e cargo que ocupa, comprometer-se individualmente com a construção de um local de trabalho harmônico, estabelecendo um pacto pessoal consigo e com os demais colaboradores de que tudo fará para enaltecer o SER HUMANO [maiúsculas do original] dentro das relações de trabalho, sendo ele próprio exemplo de Qualidade de Vida, encorajando, colaborando, facilitando e/ou agilizando cada atividade executada.

A política de Qualidade de Vida no Trabalho CBTU/METROREC é reconhecida por esta Superintendência, que no uso de suas atribuições assegurará seu cumprimento, comprometendo-se em buscar e disponibilizar os recursos humanos, materiais e financeiros que se fizerem necessários, tornando-a perene a partir de sua assinatura.

QUALIDADE DE VIDA: ABRACE ESSA IDÉIA [maiúsculas do original]”

(METROREC, 2005, p.5)

Inicialmente, demonstra que a organização, por estar altamente empenhada no programa, garante "os recursos necessários em sua dotação anual”. Ao sinalizar essa disposição no discurso, o propósito é mostrar que a parte da empresa está sendo assegurada e que, portanto, é esperada a resposta, sob a forma de compromisso, do trabalhador. Essa forma de argumentação demonstra a adoção de uma modalidade discursiva impositiva cujo tom aleivoso disfarça seu conteúdo e confunde o trabalhador, fazendo-o se sensibilizar com o programa.

Embora o discurso apresente essa abordagem dissimulada, nos trechos posteriores assume uma posição mais declarada, impondo ao trabalhador o comprometimento individual de participação. Afinal, se o interesse é de cada funcionário, se as ações do programa vão beneficiar cada um, porque é preciso exigir a adesão? Não seria natural o compromisso? Esses questionamentos revelam que, na realidade, o trabalhador não considera que o programa lhe seja benéfico e que, mesmo imposto de forma camuflada, ele resiste a mais essa algema social que lhe é colocada. É justamente nesse sentido que é preciso recorrer ao discurso ideológico para angariar o comprometimento. 
Neste trecho, os vaivéns retóricos são dedicados à busca da participação e se alternam entre as tentativas de convencimento do trabalhador e a sinalização das contrapartidas organizacionais, em geral, sob forma de disponibilidade de verbas, de recursos materiais e do compromisso da superintendência. Assim, adota a barganha política, pois ao oferecer aquilo que o trabalhador necessita, tenta comprar-lhe sua adesão individual.

\section{Conclusões}

Feitas essas considerações, podemos concluir que, de uma maneira geral, todo o documento obedece a um jogo de linguagem, ora centrado nos indivíduos, ora nos resultados organizacionais, num movimento de construção constante. Ao analisá-lo, verificamos que as necessidades humanas dos trabalhadores estão sempre atreladas ao quanto e como podem contribuir para a organização.

Esmiuçar o discurso do programa de QVT do Metrorec permitiu identificar os interesses que o movem e que estão por trás dos recursos e das ferramentas retóricas.

O modelo proposto por Chouriaraki e Fairclough (1999) é bastante instrumental para a compreensão desses propósitos subjacentes à lógica organizacional da QVT. A análise feita a partir desse enquadre da análise crítica do discurso sobre o documento é apresentada a seguir: 
Tabela 3

Análise da lógica subjacente ao programa de QVT do Metrorec a partir do enquadre para ADC de Chouriaraki e Fairclough

1. Um problema Índices altos de doenças ocupacionais como alcoolismo, depressão, estresse, hipertensão e sedentarismo, gerando baixa produtividade no trabalho.

2. Obstáculos

para serem

superados (a) Análise da conjuntura

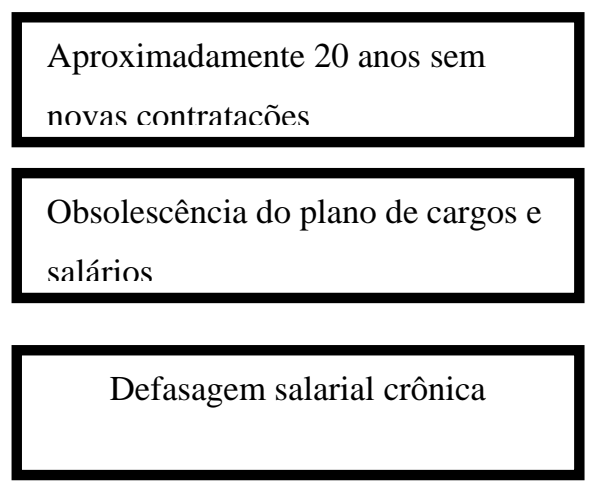

Sobrecarga de trabalho

Inadequação dos cargos às

funções e estagnação funcional

Baixa condição de vida dos

trabalhadores

Alto nível de endividamento

Busca por funções gratificadas

Busca por complementação

salarial através de horas extras e

periculosidade (b) Análise da prática em (i) Práticas relevantes particular

(ii) Relações do discurso com

outros momentos da prática

(c) Análise do discurso $\quad$ (i) Análise estrutural
Instauração do comitê executivo de QVT

Reuniões quinzenais do comitê

Cerimônia simbólica da abertura do programa de QVT

Veiculação do boletim do comitê, que publicam as ações desenvolvidas pelo comitê Implantação das principais ações de QVT na organização: ginástica laboral, reforma no refeitório e proibição do tabagismo no ambiente de trabalho, entre outras.

Associação entre o programa de QVT e a Semana de Prevenção de Acidentes do Trabalho;

Relação da QVT com outras cerimônias organizacionais, tais como confraternizações natalinas, Dia do Trabalhador etc.

Faz uso de uma modalidade impositiva;

Repleto de pressuposições

Com um ethos persuasivo que alude implicitamente a relação de poder,

Busca a legitimação das ações através de ferramentas que torna genérica a responsabilização (nominalização e transitividade);

(ii) Análise interacional

Uso de jogo retórico, ora centrado nos indivíduos, ora nos resultados organizacionais, num movimento de articulação e construção constantes. 
3. Função do problema na prática

4. Possíveis maneiras de superar os obstáculos

5. Reflexão sobre a análise
Incrementar o desempenho no trabalho através da redução das doenças ocupacionais e da melhoria das condições físicas, mentais e psicológicas do trabalhador.

Através da redução da incidência de doenças ocupacionais como o alcoolismo, estresse, sedentarismo, depressão etc.

Através da melhoria do ambiente de trabalho e das condições de trabalho (clima, refeitórios, ergonomia etc.)

Através da oferta de benefícios sociais (como academia de ginástica na organização, refeitório com alimentação balanceada,

orientação médico-odontológica etc). que compensem as condições de trabalho precarizadas pelo processo de expansão organizacional.

O programa de QVT da organização surgiu com o propósito de solucionar problemas de desempenho no trabalho. Portanto, sua lógica é instrumental, uma vez que tem na melhoria da qualidade de vida o meio para alcançar resultados de desempenho superiores, desgastados por fatores contextuais históricos.

Fonte: Chouriaraki e Fairclough (1999, p.60). 
Os efeitos impostos pelo discurso deixam transparecer a forma como é operada a ideologia nele contida. Ou seja, é através da análise de como as legitimações decorrentes dessa representação contribuem para a conservação ou a transformação de relações de dominação que se mostra como é exercida essa ideologia. Daí, portanto, a necessidade de se expor os efeitos, para evitar a continuidade da dominação (RESENDE; RAMALHO, 2006).

Thompson (1995) classifica os tipos gerais de operação de ideologia através desses efeitos. Esse esquema proporciona ferramental para se analisar linguisticamente as construções discursivas revestidas de ideologia. A figura 2 adapta essa classificação para fins deste artigo.

Figura 2

Modos de operação da ideologia

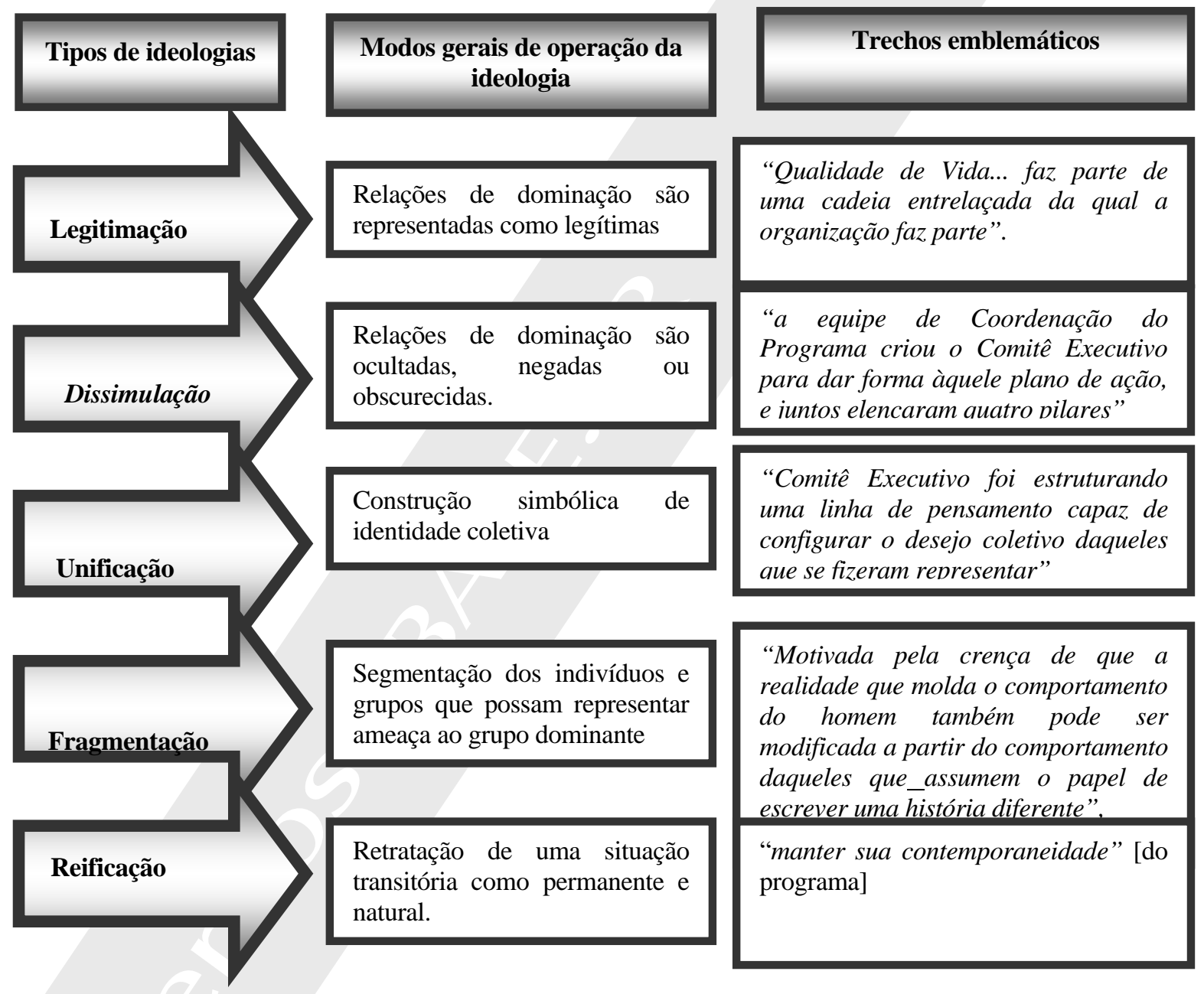

Fonte: adaptado de Thompson (1995) por Resende e Ramalho (2006). 
De acordo com essa classificação, pode-se inferir que a forma como é operada a ideologia subjacente à lógica organizacional da QVT no Metrorec é predominantemente através da dissimulação, uma vez que são ocultadas e obscurecidas no seu discurso as relações de dominação a ele inerentes.

Assim, em geral, são freqüentes no documento os momentos em que fica indefinido qual o papel dos empregados e da organização. Nesses trechos, são usadas modalidades persuasivas, através da retórica do interesse organizacional pelo bem coletivo, para confundir os trabalhadores a respeito dos seus reais propósitos.

Em outros, podemos observar uma tentativa de unificação ideológica quando o discurso da QVT faz uso de mecanismos simbólicos, tais como cerimônias, marco de referência e a própria constituição do comitê executivo do programa, para criar uma identidade coletiva dos trabalhadores como comprometidos com a qualidade de vida, "sendo ele próprio um exemplo de qualidade de vida." (METROREC, 2005, p.6)

Portanto, o efeito esperado pela ação manipuladora do discurso da QVT está claro: trata-se de uma maneira eficaz de ocultar a dominação presente na relação trabalhador/empresa, no sentido de buscar sua participação e seu comprometimento com a solução dos efeitos negativos de seu trabalho, que se acumulam e comprometem seu desempenho. 


\section{Referências}

ARENDT, Hannah. A condição humana. Rio de Janeiro. Forense Universitária, 2004.

CHOURIARAKI, Lillie; FAIRCLOUGH, Norman. Discourse in late modernity: rethinking critical discourse analysis. [S.L.]: Edinburgh University Press, 1999.

FAIRCLOUGH, Norman. New labour, new language. Londow. Routledge, 2000.

Discurso e mudança social. Brasilia: Editora, UNB, 2001.

GODOI, Christiane K. Análise do discurso na perspectiva da interpretação social dos discursos. uma possibilidade aberta aos estudos organizacionais. Revista Gestão.Org, v.3, w.2, maio/ago. 2005.

METROREC, Programa de Qualidade de Vida. CBTU/METROREC, Setembro, 2005.

MISOCZKY, Maria Ceci. O campo da atenção à saúde após a Constituição de 1988: uma narrativa de sua produção social. Porto Alegre: Dacasa Editora, 2002.

Análise crítica do discurso. uma apresentação. Revista Gestão.Org, v.3, w.2, maio/ago. 2005.

OLNO, Vânia; MISOCZKY, M. C. A. As estratégias discursivas presentes na origem do referencial para $\sigma$ desenvolvimento sustentável: uma análise crítica do Relatório de Brundtland. In. ENCONTRO ANUAL DA ASSOCIAÇÃO NACIONAL DOS PROGRAMAS DE PÓS-GRADUAÇÃO EM ADMINISTRAÇÃO, 27., 2003, Atibaia. Anais... Rio de Janeiro. Anpad, 2003. 1 CD-ROM.

RESENDE, Viviane de M.; RAMALHO, Viviane. Análise de discurso crítica. São Paulo. Contexto, 2006.

THOMPSON, J. B. Ideologia e cultura moderna. Petrópolis: Vozes, 1995.

WIDDICOMBE, S. Autobiography and change: rhetoric and authenticity of "gothic" style. In. BURMAN, E.; PARKER, 1. (Ed.). Discourse analytical research: readings and repertoires of texts in action. Londow: Routledge, 1993. 